\title{
INCIDENCE OF EPISTAXIS IN A TERTIARY HOSPITAL IN GHANA
}

\author{
P. Awuah, G. K. Amedofu and M. Duah \\ Department of Eye, Ear, Nose and Throat, School of Medical Sciences, KNUST, Kumasi, Ghana. \\ Corresponding Author's E-mail: drawuah@yahoo.com
}

\begin{abstract}
Epistaxis is defined as bleeding from the nasal cavity. It is a very common Otorhinolaryngological problem that often presents as an emergency to the outpatient departments of most hospitals worldwide. Its true incidence is often very difficult to assess. This study was aimed at analyzing aetiology, treatment and management outcome of patients who presented with epistaxis at Komfo Anokye Teaching Hospital (KATH), Kumasi, Ghana. This is a three year retrospective study (Jan2007-Dec 2010). All cases of epistaxis that presented at the Ear, Nose and Throat (ENT) clinic at $\mathrm{KATH}$ ) or referred from the polyclinics and the district hospitals were included. A total number of 96 cases were seen with epistaxis over a period of three years. There were $63(66 \%)$ males and $33(34 \%)$ females. Their ages ranged from 1-80 years. The commonest cause of epistaxis was idiopathic with 51 (53\%) cases followed by nasal trauma with 11 (11.5\%) cases and nasopharyngeal carcinoma 8 (8.3).This study supports the clinical usefulness of conservative management in the treatment of patients with epistaxis.
\end{abstract}

Keywords: Epistaxis, Nosebleed, Idiopathic, aetiology, incidence

\section{INTRODUCTION}

Epistaxis is a frequent otolaryngologic emergency (Eziyi, et al., 2009). It is a symptom of a large number of widely diverse conditions. It has been reported that up to $60 \%$ of the general population will experience at least one episode of epistaxis in their life time, and $6 \%$ will seek medical attention for it (Schaikin, 1987). Some authors portray epistaxis as a disease of the young, whereas others have noted epistaxis to be more common in the elderly (Eziyi, 2009). The causes of epistaxis include both local and systemic factors such as trauma, tumours, infection, blood dyscrasias, ureamia, cardiovas- cular diseases, and allergic rhinitis. However, the aetiology is idiopathic in majority of cases (Khtoum, 2008).

The vast majority of nose bleeds occur in the anterior part of the nose from the nasal septum. This area is richly endowed with blood vessels (Kiesselbach's plexus). This region is also known as Little's area. Bleeding farther back in the nose is known as a posterior bleed and is usually due to rupture of the sphenopalatine artery or one of its branches. Posterior bleeds are often prolonged and difficult to control. They can be associated with bleeding from both 
nostrils and with a greater flow of blood into the mouth. Treatment modality is divided into non-surgical (non-interventional / conservative) and surgical (interventional). The noninterventional therapy includes anterior nasal packing, posterior nasal packing with catheters, balloons or packs, and local cauterization (chemical or electro-cutlery) (Okafo, 1984). The surgical approaches include cryotherapy, submucosal septal resection, endoscopic cauterization, arterial ligation and endovascular embolisation of maxillary or ethmoidal arteries. The causes, management and outcome of patients who presented to our hospital with epistaxis were studied and analyzed.

\section{PATIENTS AND METHODS}

This was a retrospective review of cases of epistaxis managed in the Ear Nose and Throat Department of Komfo Anokye Teaching Hospital (KATH) Kumasi, over a three-year period January 2007-December 2010. The records of ninety-six cases of epistaxis managed in our unit during this period were retrieved. Information on socio-demographic characteristics (age, sex, occupation) were retrieved as well as duration of epistaxis before presentation. The causes of epistaxis and the modalities of management were also entered into the data form.

\section{RESULTS}

As can be seen in Table 1, a total of ninety-six cases of epitaxis were seen. There were sixtythree (63) males (66\%) and thirty-three (33) females $(34 \%)$. Their ages range from 1 to 80 years. Peak incidence was in the age group 3140 years. Table 2 shows the aetiological factors of epistaxis in this series. The results showed that the most common cause of epistaxis is idiopathic (53\%), nasal trauma (11.5\%), nasopharyngeal carcinoma $(8.3 \%)$, nasal tumours $(8.3 \%)$, hypertension $(5.2 \%)$, sinusitis $(7.3)$ and so on.

We also see in Table 3, the site of epistaxis in the patients. We do note that bleeding in the right nose was more common than the left. In a few patients, bleeding in both nasal cavities occurred. Table 4 summarizes the treatment options applied to control epistaxis. Ninety five patients $(99 \%)$ responded to non-surgical treatment.

Anterior nasal packing was the most common procedure followed by posterior nasal packing. Cauterization was used on two patients and a surgical approach in arterial litigation was used on only one patient.

Table 1: Age, gender and distribution of epistaxis

\begin{tabular}{lllll}
\hline Age & Males & Females & Total & Percentage \\
\hline $1-10$ & 8 & 2 & 10 & $10.4 \%$ \\
$11-20$ & 10 & 4 & 14 & $14.6 \%$ \\
$21-30$ & 9 & 7 & 16 & $16.7 \%$ \\
$31-40$ & 20 & 12 & 32 & $33 \%$ \\
$41-50$ & 8 & 3 & 11 & $11.5 \%$ \\
$51-60$ & 5 & 3 & 8 & $8.3 \%$ \\
$61-70$ & 3 & 2 & 5 & $5.2 \%$ \\
Total & $\mathbf{6 3}$ & $\mathbf{3 3}$ & $\mathbf{9 6}$ & $\mathbf{1 0 0 \%}$ \\
\hline
\end{tabular}

\section{DISCUSSION}

Epistaxis is an ever-present clinical problem and is one of the most common rhinologic emergencies in most ENT units. The most common procedure used in this study was anterior packing, followed by posterior nasal packing. The anterior/posterior packing was kept in situ for two days before removal.

Cauterization was used on two patients and a surgical approach in arterial litigation was used on only one patient. We normally prescribe any sedative in this operation but the commonest one used in this study was diazepam. In cases that did not yield to anterior and posterior packing maxillary artery litigation through Caldwell -luc operation was done. 
Epistaxis in Ghana...

Table 2: Aetiological factors of epistaxis

\begin{tabular}{lll}
\hline $\begin{array}{l}\text { Aetiological } \\
\text { factors }\end{array}$ & $\begin{array}{l}\text { Number of } \\
\text { patients }\end{array}$ & Percentage \\
\hline Idiopathic causes & 51 & 53 \\
Nasal trauma & 11 & 11.5 \\
$\begin{array}{l}\text { Nasopharyngeal } \\
\text { carcinoma }\end{array}$ & 8 & 8.3 \\
Sinusitis & 7 & 7.3 \\
Tumours of nose & 8 & 8.3 \\
Hypertension & 5 & 5.2 \\
Blood disorders & 2 & 2 \\
$\begin{array}{l}\text { Drugs } \\
\text { anticoagulants) }\end{array}$ & 1 & 1 \\
Liver disease & 3 & 3 \\
Total & $\mathbf{9 6}$ & $\mathbf{1 0 0}$ \\
\hline
\end{tabular}

Table 3: Sites of bleeding nose

\begin{tabular}{lll}
\hline Nasal Cavity & Number & Percentage \\
\hline Right nasal cavity & 63 & 65.6 \\
Left nasal cavities & 22 & 23 \\
Both nasal cavities & 22 & 11.4 \\
\hline
\end{tabular}

Bleeding from the right nasal cavity is more common than the left but in a few patients both nasal cavities bleed.

Again in this study, all age groups were represented. Epistaxis was found to be more common in the young adult (33\%) in the 31-40 age group. This is at variance to findings by Pallin et al. (2005) who found a bimodal age-related frequency with peaks among those younger than 10 years and age 70-79 years. Men were affected much more than women in these series. This male prepondence has been docu-
Table 4: Treatment options applied to control epistaxis

\begin{tabular}{lll}
\hline $\begin{array}{l}\text { Treatment } \\
\text { option }\end{array}$ & $\begin{array}{l}\text { Number of } \\
\text { patients }\end{array}$ & Percentage \\
\hline $\begin{array}{l}\text { Non-surgical } \\
\text { Anterior nasal } \\
\text { packing }\end{array}$ & 78 & 81.5 \\
$\begin{array}{l}\text { Posterior nasal } \\
\text { packing }\end{array}$ & 12 & 12.5 \\
$\begin{array}{l}\text { Anterior and Pos- } \\
\text { terior nasal pack- } \\
\text { ing }\end{array}$ & 3 & 3 \\
$\begin{array}{l}\text { Cauterization } \\
\text { Surgical }\end{array}$ & 2 & 2 \\
Arterial ligation & 1 & 1 \\
\hline
\end{tabular}

mented in the literature (Eziyi, 2009). The most common cause of epistaxis as revealed by this study is idiopathic (53\%) followed by nasal trauma $(11.5 \%)$ which is commonly due to road traffic accidents, nasopharyngeal carcinoma and tumour of the nose. This is at variance with the findings of others (Shahid et al., 2003; Saha et al., 2005 and Eziyi, 2009) in which majority of the patients had traumatic epitaxis. It however corroborates the work of Okafor (1984) and Brobby and Ofosu Barko (1990).

Hypertension accounted for 5\% of the cases studied. Other studies (Ogura and Senturia, 1949; Malik and Bhatiae, 1978; Rezadan and Zadan, 1999, Jackson and Jackson, 1988) have reported a high incidence of hypertensioninduced epistaxis. Though it is not documented how hypertension initiates epistaxis, it is known that the arterial muscle degeneration associated with hypertension leads to a defective muscle which jacks the power to contract, therefore leading to persistent bleeding.

As stated early, the nasal packs consists of ribbon gauze impregnated with bismuth iodo- 
form paraffin paste (BIPP) was used to control anterior epistaxis while posterior packing with Foleys Catheter balloon was found to be very effective in our practice in emergency room even in cases of profuse epistaxis. This study shows the reliability of the conservative management approach in treating epistaxis. This is consistent with the reports of Khtoum and Roosan (2008).

Materials to control epistaxis should be available in emergency rooms of hospitals in Ghana and doctors and nurses should be encouraged to know the basic anterior and posterior packing procedure.

\section{CONCLUSION}

The study comprises of cases of epistaxis. A high incident in young adults was reported with prepondence of males over females. This study supports the credibility of conservative management procedure in the treatment of epistaxis. Except for one case that required arterial ligation, all cases were treated successfully with conservative management. Hence, this approach should be the preferred option in the management of epistaxis especially in developing countries.

\section{ACKNOWLEDGEMENT}

We express our appreciation to Mr. Anthony Atta-Effa, the departmental secretary for his invaluable secretarial services.

\section{REFERENCES}

Brobby, G. W. and Ofosu Barko, F. O. (1990). Aetiology, Management and complications of Epitaxis at Komfo Anokye Teaching Hospital, in Ghana. JGMA, 24: 144-148.

Eziyi, J. A. E., Akinpelu, O. V., Amusa, Y. B. and Eziyi, A. K. (2009). Epistaxis in Nigerians. East and Central Journal of Surgery, 14 (2): 93-97.

Jackson, R. T. (1988). Factors associated with active refractory epistaxis. Arch.Otolaryngol. Head and Neck Surgery, 114: 862-865
Khtoum, N. A. and Roosan, M. A. (2008). Evaluation of conservative measures in the treatment of epistaxis. Khartoum Medical Journal, (1)1: 15-17

Ogura, J. H. and Sentura, B. H. (1949). Epistaxis. Laryngoscope, 59: 743-763

Okafor, B. C. (1984). Epistaxis: A clinical study of 540 cases. Ear, Nose and Throat Journal. 63: 153-159

Shahid, A., Sam, M. and Mohammed, S. (2003). Epistaxis: Etiology and Management. Ann King Edward Med. Coll., 9(4): 272-4.

Saha, S., Chandra, S., Moudal, P. K. Das, S. and Mishra, S. (2005). Emergency cases in a Medical College, Kolkata, Int. Journal of Head and Neck Surgery, 57(3): 219-225

Pallin, D. J., Chng, Y., Mckay, M. P. and Emond, J. A. (2005). Epidemiology of epitaxis in US emergency departments. Annals of emergency medicine, 46 (1): 77-81

Schaitkin, B., Strauss, M. and Houck, J. R. (1987). Epistaxis: Medical vrs Surgical therapy. Laryngoscope, 97, 1392-1396

Razdan, U. and Zada, R. M. (1999). Epistaxis: Study of aetiology, site and side of bleeding. Indian J. Med. Science, 5: 545-52.

Schaitkin, B., Strauss, M. and Houck, J. R. (1987). Epistaxis: Medical vrs Surgical therapy. Laryngoscope. 97: 1392-1396

Khtoum, N. A. and Roosan, M. A. (2008). Evaluation of conservative measures in the treatment of epistaxis. Khartoum Medical Journal, 1 (1): 15-17

Okafor, B. C. (1984). Epistaxis: A clinical study of 540 cases. Ear, Nose and Throat Journal, 63: 153-159 
Pallin, D. J., Chng, Y. Mckay, M. P. and Emond, J. A. (2005). Epidemiology of epitaxis in US emergency departments. Annals of emergency medicine, 46 (1): 77-81

Razdan, U. and Zada, R. M. (1999). Epistaxis: Study of aetiology, site and side of bleeding. Indian J. Med. Science, 53: 545-52.

Malik, M. K. and Bhatia, B. P. R. (1978). Indian
Medical Gazette, 112: 56-59

Jackson, K. R. and Jackson, R. T. (1988). Factors associated with active refractory epistaxis. Arch. Otolaryngol. Head and Neck Surgery, 114(2): 862-865.

Razdan, U. and Zada, R. M. (1999). Epistaxis: Stuidy of aetiology, site and side of bleeding. Indian J. Med. Science, 53: 545-52. 